\title{
Tympanometry in Neonates- A Comparative Study
}

\author{
Dessai Teja Deepak*, Mereen Rose Babu and Anupama PS \\ Nitte Institute of Speech and Hearing, India \\ Submission: November 26, 2016, 2016; Published: February 17, 2017 \\ *Corresponding author: Teja Deepak Dessai, Lecturer, Department of Audiology and Speech Language Pathology, Nitte Institute of Speech and \\ Hearing, Mangalore, Dakshina Kannada, India, Email: dessaiteja@gmail.com
}

\begin{abstract}
Objective: Impairment to hearing during childhood may lead to delay in the speech and language skills, making the communication process more difficult. Early identification and rehabilitation can benefit the children. It is necessary to test the hearing using accurate test procedures. Thus, aim of the study was to compare the use of probe tones $(226 \mathrm{~Hz}$ and $1000 \mathrm{~Hz}$ probe tone $)$ in tympanometry while testing the neonates for hearing before getting discharged from hospital setup.

Method: An inclusion - exclusion criteria was applied in selection of 60 neonates (1-17days). Hearing screening with comparison of $226 \mathrm{~Hz}$ and $1000 \mathrm{~Hz}$ probe tone in tympanometry was carried out using a comparative study design. Pressure ranging from +200 to $-400 \mathrm{daPa}$ and a pressure change rate of $600 / 200 \mathrm{daPa}$ per second was used for testing. Intensity of probe tone was adjusted at $85 \mathrm{~dB}$ SPL. Comparison was made for type of tympanogram, ear canal volume, compensated static peak acoustic admittance and tympanometric peak pressure. Sampled paired $t$ test was used to carry out statistical analysis.
\end{abstract}

Results: $1000 \mathrm{~Hz}$ probe tone surpassed the $226 \mathrm{~Hz}$ probe tone in testing the neonates using tympanometry. A statistically significant difference was observed in all the sub-sections except similar values for ear canal volume.

Conclusion: Many changes occur in the ears of neonates like changes in bone density, mesenchymal loss which has an impact on the mechanical properties of the auditory canal and middle ear system. Thus, $1000 \mathrm{~Hz}$ probe tone in tympanometry serves a promising tool.

Keywords: Probe tone; Neonates; Immittance audiometry

Abbreviations: DPOAE: Distortion Product Otoacoustic Emissions; SP: Single-peaked tympanogram; TPP: Tympanometric peak pressure; DP: Double-peaked tympanogram; IP: Inverted peaked tympanogram; A: Asymmetric tympanogram; F: Flat peaked tympanogram; Ymt: Compensated static peak acoustic admittance; ECV : Ear Canal volume

\section{Introduction}

Normal hearing ability is the main source for development of speech and language skills. Any impairment to hearing during childhood may lead to delay in the speech and language skills, making the communication process more difficult. However, early identification and rehabilitation if given can work for the benefit of the children. Therefore in neonates, it is recommended to carry out a complete hearing evaluation before moving out from the hospital setup post delivery. In addition, it is necessary to focus on the test battery used for testing the hearing of neonates. In accordance with the literature, there still persists a debate on using $226 \mathrm{~Hz}$ probe tone and $1000 \mathrm{~Hz}$ probe tone for testing the neonatal hearing.

Tympanometry is an umbrella term encompassing impedance, admittance, and their components. It is defined as mechanical analysis of the auditory system in response to acoustic stimulation. Acoustic immittance measures the acoustic energy transfer that occurs when sound pressure is applied to the tympanic membrane causing its movement. Thus it helps to evaluate the ease or opposition to this sound energy flow within the auditory system. Today, its contribution to clinical diagnosis has aided to better middle ear status diagnosis and has now become a routine part of the audiological test battery approach ranging towards neonates to geriatrics.

In the early years of life up to two years, normal ear tympanicossicular system acts differently as mass is the dominating physical feature of the ear. After this age, reaching the adult stage, there is a change in behavior which is controlled by stiffness and is better evaluated using probe frequency of $226 \mathrm{~Hz}$ [1]. Thus carrying out conventional tympanometry using $226 \mathrm{~Hz}$ probe tone at early years of life may not serve of much help. Therefore, condition of the middle year in the early stages of life can be evaluated more expeditiously using high frequency probe tones such as $678 \mathrm{~Hz}$ and 
$1,000 \mathrm{~Hz}$. Conventional tympanometry using $226 \mathrm{~Hz}$ probe tone in neonates and infants has been used by many audiologists [1-4], although the literature shows that the use of a single frequency is not sensitive enough to detect all cases of middle ear pathology, which hinders accurate diagnosis [5 -8].

Tympanometry using high frequencies help to clear up the false-positive screening results that pass off due to pathology in the middle ear or the presence of secretion. Adequate middle ear assessments in the neonatal period results in suitable medical and audiological referrals and can thereby improve the efficacy of newborn hearing screening programs [9]. Evidence from previous literature suggests that the use of a single frequency probe is not highly sensitive enough to identify all cases of middle ear alterations, thereby making diagnosis difficult. Therefore, the purpose of this study was to characterize tympanometry measurements in neonates between 0-17days of age using 2 probe tones.

\section{Materials and Method}

The study was undertaken with the approval of ethical committee formed at Nitte Institute of Speech and Hearing, Mangalore. To conduct the study, following inclusion criteria was considered for the participants of the study:

\section{A. Neonates of 1 to 17 days,}

B. Neonates administered and screened for high risk register using Joint Committee on Infant Hearing [10] to rule out possible presence of hearing impairment,

C. Ear canal screened to examine the possible obstacles,

D. Neonates with bilateral Distortion Product Otoacoustic Emissions (DPOAE) present.

A Term of Free and Informed Consent form was furnished to the Parents/caregivers which contained information about the study in very clear and uncomplicated language. Once the parental consent was signed and obtained the study was continued. The study incorporated 60 neonates: 21(35\%) female and 39 (65\%) . The age ranged between from 1 day to 17 days, with an average age of 2.9 days of life. A total of 120 years were evaluated right (100\%) and left (100\%).

Audiological interview was carried out to begin with the screening assessment, which was followed by visual inspection of the pinna and ear canal, Distortion Product Oto-acoustic Emission testing and tympanometry measurements. Audiological interview in collaboration with information from hospital files was carried out with the parents/caregivers using leading questions, in simple and uncomplicated language. The purpose was to serve the information regarding neonatal hearing, presence of any upper respiratory tract infection, and high risk indicators for hearing impairment.

Visual inspection of the pinna, ear canal and tympanic membrane was carried out by an experienced clinical audiologist to rule out any disturbances in testing of tympanometry. If any disturbances were encountered the neonate was referred to the Oto-rhino-laryngologist for the further evaluation.

To acquire the tympanometry measurements, Interacoustics AT $235 \mathrm{~h}$ impedance audiometer was used. Following the specifications of the equipment manual, tympanometry was applied using $226 \mathrm{~Hz}$ and $1000 \mathrm{~Hz}$ frequencies, with the pressure ranging from +200 to $-400 \mathrm{daPa}$ and a pressure change rate of $600 / 200 \mathrm{daPa}$ per second. The intensity of probe tone was adjusted at $85 \mathrm{~dB}$ SPL for $226 \mathrm{~Hz}$ and $1,000 \mathrm{~Hz}$.

Two forty tympanograms were obtained: 114 (95\%) with a $226 \mathrm{~Hz}$ probe tone, 109 (90.8\%) with a 1,000 Hz probe tone. The occlusion encountered during the testing procedure lead to unequal distribution of the tympanograms. In the consequence of occlusion with a $226 \mathrm{~Hz}$ and $1000 \mathrm{~Hz}$ probe tone, the probe was removed from ear and repositioned to restart the testing.

The obtained Tympanogram shapes were categorized as either a single-peaked tympanogram (SP) with maximum tympanometric peak pressure (TPP), a double peaked tympanogram (DP) with two-peak TPP, an inverted peaked tympanogram (IP) with an inverted TPP, an asymmetric tympanogram (A) with a gradual decline of TPP ranging from +200 to $-200 \mathrm{daPa}$ and, or a flat peaked tympanogram (F) with no TPP. Similarly, compensated static peak acoustic admittance (Ymt) mentions the maximum peak admittance, where the pressures of the external and middle ear are equal. The maximum admittance peak pressure is expressed in daPa.

With the previous literature [10-12], using $226 \mathrm{~Hz}$ probe tone SP or DP tympanograms were classified as normal. For $1,000 \mathrm{~Hz}$ frequency, tympanograms were classified using the Sutton Protocol [13], used for infants upto the age of 4 months. Shadowing this protocol, tympanograms with $\mathrm{Ymt}>0$ and $\mathrm{TPP}>-200 \mathrm{daPa}$ were considered as normal. Tympanograms with $\mathrm{Ymt}<0$ or TPP $<-$ $200 \mathrm{daPa}$ were considered as abnormal. On classification of tympanograms as either normal or abnormal, the tympanograms with the two different probe tones were compared. In addition, to the literature, single-peaked and double-peaked tympanograms are considered normal, while asymmetric, inverted, and flat tympanograms are considered abnormal [13-16].

\section{Results}

Tympanometry was carried out in 60 healthy neonates using $226 \mathrm{~Hz}$ and $1000 \mathrm{~Hz}$ probe tone. The tympanometry measures were compared in accordance with type of tympanogram, ECV, Ymt, TPP. The obtained measures for $226 \mathrm{~Hz}$ and $1000 \mathrm{~Hz}$ were compared to know the efficacy of the probe tones. Sampled paired t test using SPSS version: 16 was used to obtain a statistically significant difference between the two probe tones.

On comparing the type of tympanograms, $226 \mathrm{~Hz}$ elicited 71 Single Peaked tympanogram with maximum tympanometric peak pressure and 49 flat peaked tympanogram (F) with no 
TPP. However, $1000 \mathrm{~Hz}$ elicited 83 Single peak tympanogram with maximum tympanometric peak pressure, 26 double peak tympanograms with two-peak TPP and 11flat tympanogram with no TPP (Figure 1).

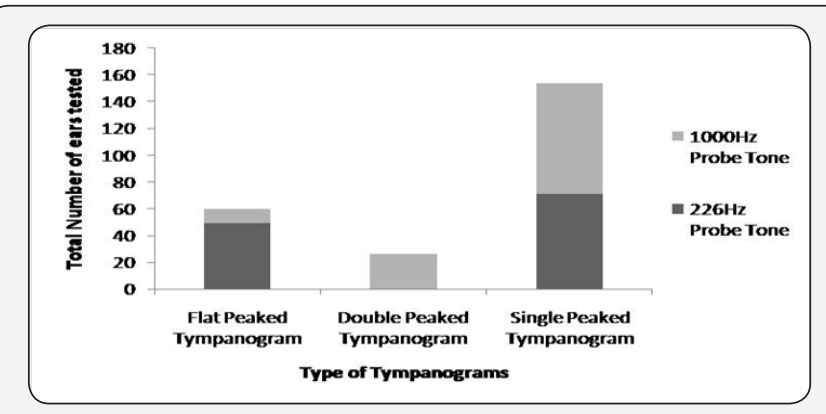

Figure 1: Represents the types of tympanograms obtained using $226 \mathrm{~Hz}$ and $1000 \mathrm{~Hz}$ probe tone in neonates.

Using sampled paired t test it is evident that $1000 \mathrm{~Hz}$ probe tone is more compatible for neonatal hearing testing then $226 \mathrm{~Hz}$ probe tone with respect to ECV, Ymt and TPP. However there is a significant difference between the ECV and Ymt. Table 1 shows the statistical differences between the three parameters (Table 1).

Table 1: Comparison between $226 \mathrm{~Hz}$ and $1000 \mathrm{~Hz}$ probe tone.

\begin{tabular}{|c|c|c|c|c|}
\hline \multirow{2}{*}{ Parameters } & $\begin{array}{c}\text { 226Hz } \\
\text { Probe } \\
\text { Tone }\end{array}$ & $\begin{array}{c}1000 \mathrm{~Hz} \\
\text { Probe Tone }\end{array}$ & \multirow{2}{*}{$\begin{array}{c}\text { T } \\
\text { value }\end{array}$} & \multirow{2}{*}{ P value } \\
\cline { 2 - 4 } & \multicolumn{2}{|c|}{ Mean Value } & \\
\hline ECV & $0.74 \mathrm{~cm} 3$ & $0.71 \mathrm{~cm} 3$ & 0.94 & $\mathrm{P}<0.05$ \\
\hline Ymt & $0.33 \mathrm{~cm} 3$ & $0.45 \mathrm{~cm} 3$ & -3.56 & $\mathrm{P}>0.05$ \\
\hline TPP & $-31.33 \mathrm{dapa}$ & $-12.07 \mathrm{dapa}$ & -3.08 & $\mathrm{P}>0.05$ \\
\hline
\end{tabular}

Using the $226 \mathrm{~Hz}$ and $1000 \mathrm{~Hz}$ probe tone, the ECV values were almost the same. There was less variation observed using $226 \mathrm{~Hz}$ and $1000 \mathrm{~Hz}$ probe tone frequencies. The sampled paired test revealed no significant difference for the same. However, using $226 \mathrm{~Hz}$ and $1000 \mathrm{~Hz}$ probe tone Ymt and TPP were not the same. Sampled Paired t test revealed a significant difference between Ymt and TPP using $226 \mathrm{~Hz}$ and $1000 \mathrm{~Hz}$ probe tone in neonates.

A significant difference was observed, when the $226 \mathrm{~Hz}$ and $1000 \mathrm{~Hz}$ probe tone frequencies were compared. This indicates that the $1000 \mathrm{~Hz}$ probe tone surpassed the limitations of $226 \mathrm{~Hz}$ probe tone in the mass dominating middle ear system of the neonates with better measurements.

\section{Discussion}

The results were earned by grouping the right and left ears to facilitate better statistical analysis, as there was no significant difference found between the ears in the previous studies. In the present study a statistically significant difference across two subsections was seen.
It determines compensated static acoustic admittance. For $226 \mathrm{~Hz}$ probe tone, the normal range of ECV is between 0.3 and $1.0 \mathrm{~mL}$ [17-19]. Literature reports a mean of about $1.5 \mathrm{~mm}$ [6,11]. GRASON-STADLER [20] reports, ECV values acquired with a frequency of $678 \mathrm{~Hz}$ are 3 times larger than the ECV values obtained at $226 \mathrm{~Hz}$, and that at 1,000 $\mathrm{Hz}$ probe tone. This difference can be up to 4.4 times larger. The current study reports that the ECV values obtained using high frequencies are greater with $1000 \mathrm{~Hz}$ than values obtained with $226 \mathrm{~Hz}$. Consistent with this statement, a significant difference between the results of the 3 frequencies was found, with the mean ECV value at $1,000 \mathrm{~Hz}$ greater than the mean values at $678 \mathrm{~Hz}$ and $226 \mathrm{~Hz}$ [14].

In the present study $226 \mathrm{~Hz}$ probe tone obtained single and flat peaked tympanograms however; $1000 \mathrm{~Hz}$ probe tone lead to single, double and flat peaked tympanograms. The possible tympanometry measures leading to differences in the type of peaks could be attributed to the possible presence of cerumen in the ear canal, placement of the probe in the infant ear, or differences in the middle ear system of infants [20]. Similarly, the presence of unequal distribution in number of tympanograms could be due to the presence of occlusion effect. Infants younger than 4 months old have higher chance of obtaining occlusion effect during the testing [11] and a low occurrence of flat tympanograms, indicate possible presence of fluid in the middle ear.

Similarly, literature reports, occurrence of single-peaked tympanograms to be predominant $[11,20]$, while other studies indicate a preponderance of double-peaked tympanograms in neonates and infants using $1000 \mathrm{~Hz}$ probe tone [12,21]. In addition, a higher incidence of single-peaked tympanograms $[11,14]$, followed by flat tympanograms is also quoted [14]. Single-peaked and double-peaked tympanograms are considered normal, while asymmetric, inverted, and flat tympanograms are considered abnormal [13-16]. Literature reports different findings with $226 \mathrm{~Hz}$ and $1000 \mathrm{~Hz}$ probe tones. The uncommon characteristics of the tympanograms obtained from newborns and babies, may be attributed to the physiological differences concerning the ears from newborns and adults [22]. Literature reports high frequency tympanometry provides more detailed information about the state of the mechanics and acoustics of the ear, especially for changes related to the mass factor [23-24], as well as the possibility of middle ear pathology at the initial or final stage. To conclude, $1000 \mathrm{~Hz}$ probe tone reduces prevalence of flat tympanograms in newborns and $1000 \mathrm{~Hz}$ probe tone has also been identified as having greater sensitiveness to identify mild middle ear disorders [25].

The differences observed in obtaining tympanometric curves in neonates can be attributed mainly to normal variations in the subject population and also by the differences in the age of neonates. During growth there are many changes that occur in the ears of neonates, which have an impact on the mechanical properties of the auditory canal. Among the physical changes, 
differences are seen in the external ear and in the middle ear growth such as enlargement of the external ear, mastoid and middle ear cavity, changes in tympanic membrane orientation and tympanic annulus fusion. Some other variations such as changes in bone density and mesenchynal loss occuring during development could also play a major role. These changes could be related to the acoustic changes influencing the recording of the tympanogram with compensated static peak acoustic admittance $[6,16,26,27]$.

In addition, mass components are larger in high frequency and lower in the low frequency tympanometry $[6,22]$. The normal middle ear is primarily dominated by the stiffness of low frequency sounds $(226 \mathrm{~Hz})$. In a higher frequency (for instance: $1000 \mathrm{~Hz}$ ), the relative participation of each anatomical structure is changed and the acoustic admittance measured at the middle ear inlet becomes more predominated by the mass [12].

The admittance measurement in tympanometry indicates changes in the middle ear, literature reports higher mean Ymt values at 1,000 $\mathrm{Hz}$ compared to $226 \mathrm{~Hz}[11,13]$. Mean Ymt values equal to 1.06 mmho when evaluating neonates [28]. The results of the current study are in acceptance with the literature. On statistical analysis $1000 \mathrm{~Hz}$ probe tone obtained higher values of Ymt in comparison to $226 \mathrm{~Hz}$ probe tone. Low frequency tympanometry in newborns and babies younger than six months has low sensitivity, in other words, the high level of false-negatives.

While comparing the tympanometric peak pressure (TPP) obtained with $226 \mathrm{~Hz}$ and $1000 \mathrm{~Hz}$. The current study indicated a higher TPP value with $1000 \mathrm{~Hz}$ than with $226 \mathrm{~Hz}$. Similar findings have been reported in the literature $[3,6]$. Although there were statistically significant differences between the frequencies with respect to TPP, none of the differences were clinically significant. That is, the results for all 2 frequencies were within the normal range [13].

In addition, testing neonates using tympanometry, tympanograms with probe tone of $1000 \mathrm{~Hz}$ are reliable, easier to interpret than $226 \mathrm{~Hz}$ probe tone. It is easy to interpret and more reliable (91\%) using $1000 \mathrm{~Hz}$ than the $226 \mathrm{~Hz}$ (35\%) probe tone, which shows a significantly better result in the assessment of the middle ear system. Similarly, in infants younger than 3 months of age, $226 \mathrm{~Hz}$ probe tone resulted in 58\% of false-positive results [25].

The results of the current study are in accordance with the findings in the literature. These findings provide evidence for further obtaining normative values at different ages to adapt clinical practice to the use of high frequency probe tones with young children.

\section{Conclusion}

The current study aimed at comparing the two probe tones and its measurements in tympanometry. The neonates were considered as the subjects of the study. The difficulties met by $226 \mathrm{~Hz}$ probe tone were seen to be surpassed by $1000 \mathrm{~Hz}$ probe tone in neonatal tympanometry acoustic measurements. Neonates can be well diagnosed using a $1000 \mathrm{HZ}$ probe tone using tympanometry. However, further is warranted as the sample size used in current is small.

\section{Informed consent}

Informed oral consent was obtained from all individual participants included in the study.

\section{Ethical approval}

All procedures performed in studies involving human participants were in accordance with the ethical standards of the institutional and/or national research committee and with the 1964 Helsinki declaration and its later amendments or comparable ethical standards.

\section{References}

1. Melo JJ, Lewis DR, Marchiori LLM (2008) Resultados timpanométricos: lactentes de seis meses de idade. Rev CEFAC 10(1): 104-109.

2. Palmu AA, Syrjänen R (2005) Diagnostic value of tympanometry using subject specific normative values. Int J Pediatr Otorhinolaryngol 69(7): 965-971.

3. Smith CG, Paradise JL, Sabo DL, Rockette HE, Kurs Lasky M, et al. (2006) Tympanometric findings and the probability of middle ear effusion in 3686 infants and young children. Pediatrics 118(1): 1-13.

4. Feniman MR, Souza AG, Jorge JC, Lauris JRP (2008) Achados otoscópicos e timpanométricos em lactentes com fissura labiopalatina. Rev Bras Otorrinolaringol 74(2): 248-252.

5. De Ceulaer G, Somers T, Offeciers FE, Govaerts PJE (2002) Middle ear status in ears showing high admittance tympanograms. Clinical value of the use of the two component $678 \mathrm{~Hz}$ otoadmittance tympanogram. Acta Otorhinolaryngol Belg 56(3): 313-317.

6. Margolis RH, Bass Ringdahl S, Hanks WD, Holte L, Zapala D (2003) Tympanometry in newborn infants - $1 \mathrm{kHz}$ norms. J Am Acad Audiol 14(7): 383-392.

7. Baldwin M (2006) Choice of probe tone and classification of trace patterns in tympanometry undertaken in early infancy. Int Audiol 45(7): 417-427.

8. Linares AE, Carvallo RMM (2008) Medidas imitanciométricas em crianças com ausência de emissões otoacústicas. Rev Bras Otorrinolaringol 74(3): 410-416.

9. Swanepoel DW, Werner S, Hugo R, Louw B, Owen Rina, et al. (2007) High frequency immittance for neonates: a normative study. Acta Oto Laryngol 127(1): 49-56.

10. Joint Committee on Infant Hearing (2007) Year 2007 position statement: principles and guidelines for early hearing. Pediatrics 120(4): 898-921.

11. Carvallo RMM (1992) Medidas de imitância acústica em crianças de zero a oito meses de idade [tese]. São Paulo(SP): Escola Paulista de Medicina.

12. Silva KAL, Novaes BACC, Lewis DR, Carvallo RMM (2007) Achados timpanométricos em neonatos com emissões otoacústicas presentes: medidas e interpretações. Rev Bras Otorrinolaringol 73(5): 633-639.

13. Cazelatto AS, Collela-Santos MF (2008) Imitanciometria em lactentes com tom de sonda de 226 e $1000 \mathrm{Hertz}$. In: Anais do $16^{\circ}$ Congresso Interno de Iniciação Científica Campinas, SP. Campinas: Unicamp, Brazil. 
14. Macedo CC (2012) Timpanometria em lactentes com fissure labiopalatina utilizando sonda de multifrequência [dissertação]. Int Arch Otorhinolaryngol 16(2): 186-194.

15. Harris PK, Hurchinson KM, Moravec J (2003) The use of tympanometry and pneumatic otoscopy for predicting middle ear disease. Am J Audiol 14(1): 3-13

16. Jerger J (1970) Clinical experience with impedance audiometry. Arch Otolaryngol 92(4): 311-324.

17. Prieve BA, Calandruccio L, Fitzgerald T, Mazevski L, Georgantas LM (2008) Changes in transient-evoked otoacoustic emission levels with negative tympanometric peak pressure in infants and toddlers. Ear Hear 29(4): 533-542.

18. Margolis RH, Heller JW (1987) Screening tympanometry: criteria for medical referral. Audiology 26(4): 190-208.

19. Shanks JE, Stelmachowicz PG, Beauchaine KL, Schulte L (1992) Equivalent ear canal volumes in children pre and post tympanostomy tube insertion. J Speech Hear Res 35(4): 936-941.

20. Grason Stadler (2005) GSI Tympstar version 2-Middle ear analyzer: Reference Instruction Manual. ( $9^{\text {th }}$ edn), Madison: Grason-Stadler, USA,p.1.

21. Engel J, Anteunis L, Chenault M, Marres E (2000) Otoscopic findings in relation to tympanometry during infancy. Eur Arch Otorhinolaryngol 257(7): 366-371.
22. Kie J, Allison Levick, Dockray J, Harrys R, Kirkegard C, et al. (2003) High- frequency $(1000 \mathrm{~Hz})$ tympanometry in normal neonates. J Am Acad Audiol 14 (1): 20-28.

23. Hall JW, Chandler D (1999) Timpanometria na audiologia clínica. In: Katz, J Tratado de audiologia clínica. (4 ${ }^{\text {th }}$ edn), São Paulo: Manol, Brazil, pp. 281-297.

24.Wimmer E, Toleti B, Berghaus A, Baumann U, Nejedlo I (2010) Impedance audiometry in infants with cleft palate: the standard $226 \mathrm{~Hz}$ probe tone has no predictive value for the middle ear condition. Int J Pediatr Otorhinolaryngol 74(6): 586-590.

25. Alaerts J, Luts H, Wouters J (2007) Evaluation of middle ear function in young children: clinical guidelines for use of 226- and $1.000-\mathrm{Hz}$ tympanometry. Otol Neurotol 28(6): 727-723.

26. Holte T, Margolis RH, Cavanaugh R (1991) Developmental changes in multi frequency tympanograms. Audiology 30(1): 1-24.

27. Keefe DH, Folsom RC, Gorga MR, Vohr BR, Bulcn JC, et al. (2000) Identification of neonatal hearing impairment; ear-canal measurements of acoustic admittance and reflectance in neonates. Ear Hear 21(5): 443-461.

28. Mazlan R, Kei J, Hickson L, Gavranich J, Linning R (2010) Test-retest reproducibility of the $1.000 \mathrm{~Hz}$ tympanometry test in newborn and sixweek-old healthy infants. Int J Audiol: Early Online 49(11): 815-822.

\section{Your next submission with Juniper Publishers will reach you the below assets}

- Quality Editorial service

- Swift Peer Review

- Reprints availability

- E-prints Service

- Manuscript Podcast for convenient understanding

- Global attainment for your research

- Manuscript accessibility in different formats ( Pdf, E-pub, Full Text, Audio)

- Unceasing customer service

Track the below URL for one-step submission https://juniperpublishers.com/online-submission.php 